\title{
General Motors e meio ambiente
}

\section{Introdução}

Depois de acompanhar, através da mídia, a festaderecepção parao Governador Antonio Britto epara adiretoriadaGeneral Motors, no lançamento dapedrafundamental dasfuturas instalações da empresa, no município de Gravataí (RS), fica a pergunta, qual será o impacto ambiental de todo o empreendimento? Essa é apenas mais uma iniciativa governamental imediatista, com objetivos puramente econômicos ou serão real izados os projetos ambientais necessários? Por que não existe um Estudo de Impacto A mbiental (EIA) e por que a sociedade não foi devidamenteesclarecidanessesentido? Por quetudo isso não foi discutido abertamente?

\section{A visão fornecida pelos jornais}

A festa foi grande, com direito a banda de música, bateria de escola de samba, estouro de 10 mil fogos de artifício, balões das cores da GM, colegiais com bandeirinhas, distribuição de duas mil latas de cerveja para a população e cul minou com o descerramento de uma placa gigantesca, além do plantio de quatro mudas de árvores, entre el as uma de pau-brasil, como forma de mostrar a preocupação daempresacom relação ao meio ambiente.

A comemoração, própria da nossa sociedade tupiniquim, foi tal que surpreendeu o então presidente da GM no Brasil, Mark Hogan, o qual, conformenota publicada pel o colunista José Barrionuevo, em Zero Hora de 22 de março, solicitou ao secretário de Desenvolvimento e Assuntos Internacionais, Nelson Proença uma cópia do vídeo com as imagens do acontecimento, para mostrar em reunião

\section{Maria Cristina V. Gomes da Silva}

Mestranda em Educação A mbiental na FURG Profa. da FAMECOS/ PUCRS da corporação, em Detroit. "Seeu contar el es não acreditarão", justificou.

Durante os mais de quatro meses de 
negociações entre Governo do Estado e GM foram divulgadas quasequeapenasinformações queenal teciam os benefícios que seriam gerados pel o empreendimento: mais de $2 \mathrm{mil}$ empregos diretos na Região Metropolitana deP. A legree 10 mil indiretos, investimentos da ordem de US\$ 600 milhões, produção de 120 mil véculos por ano eainstalação demais de 30 empresas fornecedoras junto ao complexo quea GM erguerá naquelemunicípio.

“A planta gaúcha será a mais moderna da corporação no mundo. Será e primeira no país dentro do conceito de comunidade industrial e servirá de modelo para outras fábricas que a GM instalará nos próximos anos na Índia e na China", diz o Caderno de Economia da Zero Hora de 16 de março. Diversas vezes estas mesmas informações foram publicadas nos jornais analisados.

Mas o que realmente significa uma fábrica modelo? Ao se expressarem dessa maneira, estavam se referindo unicamente a equipamentos, tecnologia ou isso também englobao aspecto ambiental? O assunto foi tratado como óbvio esecundário pela imprensa, Governoe direção da GM . M eio ambiente pode ser um temaóbvio paraempresasdePrimeiroMundo localizadas no Primeiro Mundo, masisso não acontece quando el as se instal am nas nações "em desenvolvimento".

De novembro de 1996 até o dia 25 de março desteano, foram gerados mais de $10 \mathrm{mil} \mathrm{cm} /$ col nos jornais Zero Hora, Correio do Povo e Jornal do Comércio, dos quais menos de cem referiam-seaosinvestimentoseprovidências para neutralizar o impacto ambiental das futuras instalações da GM. O Caderno de Economia especial sobrea GM , publicado no Jornal do Comércio, do dia 3 de dezembro, diziaquea proposta do governo gaúcho para atrair a GM para o Estado deveria incluir o equacionamento dos efluentes, segundo o modelo adotado pelo Pólo Petroquímico de Triunfo.

De acordo com Z ero H ora de 6 de dezembro,
“oEstado seresponsabilizarápelotratamento dos resíduos, com a possível construção de uma estação de tratamento de efluentes".

O Correio do Povo, de 10 de dezembro, na matériasobreogasoduto (queintegraopacote de investimentos em infra-estrutura oferecidos à GM) reforçava dizendo que: "É certa ainda, a construção de uma estação de tratamento de efluentes".

Segundo a reportagem do Jornal do Comércio de16dedezembrointitulada"Governoenvia hojeàA L propostas sobrea GM", os prefeitos dos municípios deGuaíba, Eldorado do Sul e Gravataí deveriam responder aquestionários com questões de infra-estrutura. Eram 28 itens que, entre outros, perguntavam sobre condições para a destinação do lixo e do seu tratamento. Também o Correio do Povo de 19 de dezembro, faz rápida alusão a este questionário e a Zero $\mathrm{H}$ ora do mesmo dia refere-se ao assunto de maneira ainda mais superficial.

A notícia intitulada "GM adia a decisão sobre - local da fábrica", de Zero H ora de 14 de janeiro, informa que "a GM espera a conclusão dos estudos de impacto ambiental que a instalação da montadora provocará porque o meio ambiente integra os conceitos básicos da maior corporação do mundo".

Ainda o Correio do Povo ressalta a importância do tema para a GM. No dia 19 de janeiro, diz que:

“A Fundação Estadual de Proteção A mbiental (Fepam), incumbida de autorizar e fiscalizar a instalação da montadora, não prevêobstáculos paraa liberação do empreendimento. [...] A avaliação da Fepam em relação ao potencial poluidor dafuturamontadora pode ser explicada pelo seu conhecimento do projeto. A entidadejávisitou as três potenciais local izações da futura indústriadaGM eelaborou umrelatório prel iminar das regiões. N ão detectamos 
riscos flagrantes em nehuma delas, resume o diretor técnico da entidade, Ricardo Dobrovolski. A GM só vai definir olocal quando sua equipedisser que ele atende a todas as exigências do órgão ambiental, prevê o diretor da Fepam. A partir desta escolha, a GM vai ingressar com um pedido de licença prévia. A indústrianão precisarásolicitar um Estudo del mpacto A mbiental (EIA) [!]. Este processo é complexo e demorado, exigindoarealização deaudiências públicas para discutir o projeto. Com a dispensa, a liberação pode sair mais depressa [sic]."

Maioresesclarecimentossão publicados pelo Jornal do Comércio de 25 de março, onde o diretor-técnico do grupo gaúcho PróAmbiente, Marco Antonio Dexheirmer, declara que $20 \%$ dosUS\$600milhões da obra serão aplicados em medidas preventivas do meio ambiente. Na entrevista ele confirma a participação do Estado, sob cuja responsabilidade ficará o tratamento dos efluentes líquidos. Dizquepossivelmenteseráfeito um sistema integrado semelhante ao desenvolvido no Pólo Petroquímico, em que o gerenciamento está a cargo da Companhia Riograndense de Saneamento (Corsan) eque os efluentes cloacais deverão ser tratados e Iançados no Rio Gravataí, enquanto que os industriaispassarão por uma purificação para serem reutilizados. Segundo ele, o gerenciamento dos resíduos sólidos deverá ser terceirizado, sendo que a Pró-A mbiente é forte candidata.

Explica que estes resíduos deverão ser enviados para locais especiais, terminais em que o solo será revestido para proteger a terra, as águas e o lençol freático. Informa ainda que o controle da emissão dos gases emitidos pelas caldeiras (monóxido de carbono, dióxido de carbono, dióxido de enxofreeágua) ficarácomaGM, sendo queas opções para isso são os lavadores de gases, filtroseprecipitadores, todos encontradosno Brasil. E isso praticamente é tudo o que foi publicado sobre o assunto.

Por que a questão ambiental não obteve a merecida discussão? Por que foi relegada a um plano secundário por políticos, imprensa e pela sociedade?

\section{O desenvolvimento sustentável}

Desenvolvimento é evolução e deste modo, bem-vindo. Além disso, não passa despercebido queexistemiséria, fomeedesemprego. Porém, o progresso deve ocorrer de forma consciente e ética, respeitando o meio ambiente.

\section{“Desenvolvimento sustentável quer dizer que o desenvolvimento deve satisfazer nossas necessidades econô- micas atuais sem reduzir a capacidade dasgeraçõesfuturas defazer o mesmo." (Guimarães 1992, p.76).}

Embora o conceito de desenvolvimento sustentável continue polêmico na teoria ena prática, uma vez queo Primeiro eo Terceiro Mundo apresentam opiniões diferentes quanto ao consumoeao usufruto daprodução, existe um consenso sobre as conseqüências dos problemas (Faundez 1994, p.104).

É possível aliar progressoà preservação. Basta vontade política e econômica. Quanto a esta última, os certificados ISO chegaram para exigi-la, pois brevemente nenhum produto conseguirá participar do mercado internacional se não tiver essa certificação. A qui mesmo no Estado, algumas empresas já despertaram para isso. É o caso da Petroflex, Nitriflex e OPP Polietilenos, localizadas no Pólo Petroquímico de Triunfo, que, assim como a Riocell, de Guaíba, receberam a certificação no ano passado.

A ISO é a sigla da Internacional Standardization Organization, com sedena Suíça, que congrega representantes de 110 países. O trabal ho da ISO consisteem elaborar normas 
paraapadronização deprocessosprodutivos.

A série ISO 14000 contém um conjunto de regras que as empresas devem seguir para evitar a agressão ao ambiente, além de racionalizar a produção. As empresas interessadasemobtêlaemnível internacional precisam contratar auditorias estrangeiras, para fiscalizar os processos e rel ações com o ambientenatural. Asnormasestabelecemque além de se preocuparem com o impacto ambiental queassuasatividadespodemgerar sobrerecursoscomo o solo, água, ar econsumo de energia, as organizações devem ter objetivos e metas ambientais que envolvam desdeosfuncionários, prestadores deserviços, até a comunidade.

Depois de obtida a ISO 14000, são realizadas auditorias semestrais para averiguar se as práticasquederam direitoàcertificação estão sendo mantidas pelas empresas.

Reigota, quando se refere aos objetivos da Educação Ambiental definidos pela Carta de Belgrado, explica o quesignifica capacidade de avaliação:

“Capacidade de Avaliação é levar os indivíduoseosgruposaavaliar medidas e programas relacionados ao meio ambienteemfunção defatores deordem ecológica, política, econômica, social, estética eeducativa. Fundamental para a participação do cidadão é decifrar a linguagem dos projetos de risco ambientais elaborados por técnicos especializados. A capacidade de avaliação permite ou não que projetos duvidosos sejam efetuados. A educação ambiental deve procurar traduzir a linguagem técnico-científica para a compreensão de todos." (Reigota 1994, p. 33)

É nesse momento quea atuação da imprensa assumeextremaimportância, decifrando essa linguagem, tornando públicasequestionando as iniciativas governamentais com relação ao meio ambiente, o quenão éuma tarefa fácil.
E, segundo Peter( 1994, p.25), “o principal desafio enfrentado pelos jornalistas que cobrem este setor é traduzir o palavreado científico em linguagem clara e concisa, pois a maioria dos leitores de jornal, telespectadoreseouvintes derádio não têm tempo ou disposição para consultar dicionários a fim de decifrar os termos ecológicos".

Lembrando Reigota (1994, p.24), quando diz que os meios de comunicação, através de debates, filmes, artigos enfocando os problemas ambientais, contribuem para a conscientização da população, verifica-seque foi justamente isso que fal tou para haver um maior esclarecimento da sociedadequanto às medidas ambientais a serem tomadas com relação à GM .

Os meios de comunicação na construção da realidade

Nas primeiras décadas deste século, acreditava-se que a imprensa manipulava totalmenteas massas. A chamada "Teoria daBala Mágica", cuja idéia fundamental era que as mensagens da mídia eram recebidas de maneira uniforme pelos membros da audiência e que respostas imediatas e diretas eram desencadeadas por tais estímulos (De Fleur e Ball-Rokeach, 1993, p.182), foi posteriormente alterada e complementada.

“N a evolução muda o tipo de efeito, que já não diz respeito às atitudes, aos valores, aos comportamentos dos destinatários. É um efeito cognitivo sobre os sistemas de conhecimento que o indivíduo assume e estrutura de uma forma estável, devido ao consumo quefaz dascomunicações demassa" (Wolf, 1995, p.126). Ele explica que também muda o quadro temporal e os efeitos deixam de ser considerados pontuais, ligados à exposição à mensagem, pois observa-se que elessão cumulativos, sedimentadosnotempo.

Os cientistas dos mass media, auxiliados pela psicologia social, observaram que alguns 
princípios regiam o recebimento da mensagem. O primeiro deles refere-se ao interesse em obter a informação e ressalta que "quanto mais expostas as pessoas são a um determinadoassunto, maisoseu interesseaumenta e, à medida que o interesse aumenta, mais elas se sentem motivadas para saberem mais acerca dele" (Wolf, 1995 p.33).

O mesmo autor explica o princípio da exposição seletiva, dizendo que "os componentes da audiência tendem a expor-se à informação que está de acordo com as suas atitudes e a evitar as mensagens que, pelo contrário, estão em desacordo com essas atitudes".

O princípio da atenção seletiva alerta para o fato de que as diferenças individuais da estrutura cognitiva resultam em diversos model os de atenção ao conteúdo da mídia.

N ossas sociedades demídia estão a tal ponto saturadas com mensagens concorrentes que as pessoas não podem simplesmente atentar para tudo que lhes é dirigido. Mesmo que tentassem, sofreriam quase que instantaneamenteuma sobrecarga. Para evitar isso, as pessoas criam "filtros mentais" que vasculham colossais doses de informação. Suaatençãoéconfinadaaapenasumlimitado segmento do queestádisponível diariamente (DeFleur e Ball-Rokeach, 1993 p.215).

Também o princípio da percepção seletiva baseia-se nas diferenças individuais e alerta quedevidoadiferençasemfatorescognitivos como interesses, crenças, conhecimentos anteriores, atitudes, necessidades e valores, osindivíduosperceberãoummesmo estímulo complexo deformadiferentedeoutraspessoas portadoras deestruturas cognitivas diversas (DeFleur et Ball-Rokeach, 1993 p.216).

Ou seja, como diz Rodrigues (1988, p.203) ,"o processo perceptivo envolve uma série de variáveis que seinterpõem entre o momento da estimulação sensorial e a tomada de consciência daquilo que foi responsável por esta estimulação. A lém disso, de acordo com Wolf (1995, p.33), a interpretação transforma eadaptao significado damensagem recebida, fixando-a às atitudes e aos valores do destinatário e pode, por vezes, até mudar radicalmenteo sentido daprópriamensagem.

Pelo princípio da recordação sel etiva, "certos tipos deconteúdo serãolembrados por longo tempo por certos tipos de pessoas. Outras, com diferentes estruturas cognitivas, vinculações associativas e ligações sociais, o esquecerão prontamente" (DeFleur et BallRokeach, 1993, p.217).

Sobre o princípio da ação seletiva, os mesmos autores dizem que:

“... nem todos agirão da mesma forma por terem sido expostos a determinada mensagem da mídia. A ação éo el o final da corrente. Antes deela poder ocorrer, um membro da audiência tem de comparecer àapresentação, perceber seu significado e lembrar o seu conteúdo. Todas essas respostas dependerão das influências intervenientes de variáveis cognitivas, categorias e subculturas, e devínculossociaiscomoutraspessoas." (DeFleur et Ball-Rokeach, 1993, p.217)

A tualmente, além de todas essas novas concepções, a hipótese do agenda- setting está recebendo grande atenção por partedos pesquisadores dos mass media. Ela defende que:

“Em conseqüência da ação de jornais, da televisão e dos outros meios de informação, o público sabe ou ignora, presta atenção ou descura, realça ou negligencia elementos específicos dos cenários públicos. As pessoas têm tendência para incluir ou excluir dos seusprópriosconhecimentosaquiloque os mass media incluem ou excluem do seu próprio conteúdo. Além disso, o público tendea atribuir àquilo queesse conteúdo inclui uma importância que 
reflete de perto a ênfase atribuída pelos mass media aos acontecimentos, aos problemas, às pessoas." (Shaw, 1979, p. 96)

Foi constada a existência de grande correspondência entrea ênfase dada a determinada questão pelos veículos de comunicação de massa e o nível de importância que pessoas queestiveram expostas àmídialheatribuem. Isso não quer dizer que a imprensa tenha capacidade de levar o público a adotar qualquer determinado ponto de vista, mas ela faz com que alguns problemas sejam encarados como mais relevantes do que outros. "A agendadaimprensa éa agendado público"(DeFleur et Ball-Rokeach, 1993 p.284).

A hipótese do agenda-setting não defende que os mass media pretendam persuadir. Para ela, os mass media, descrevendo e precisando a realidade exterior, apresentam ao público uma lista daquilo sobre o que é necessário ter uma opinião e discutir. Seu pressuposto fundamental é que a compreensão queas pessoas têm de grande parte da realidade social Ihes é fornecida, por empréstimo, pelos mass media (Shaw, 1979, 96,101).

Como bem resume Cohen, "se é certo que a imprensa não pode, na maior parte das vezes, conseguir dizer àspessoas como pensar, tem, no entanto, uma capacidade espantosa para dizer aos seus próprios leitores sobre quetemasdevem pensar" (Cohen, 1963, p.13).

\section{Conclusões}

Imediatamente após o período analisado, o deputado Flávio Koutzii trouxeà tona o caso do financiamento de $\mathrm{R} \$ 253$ milhões que o Governo do Estado forneceu à GM , comjuros de $6 \%$ ao ano, cinco anos decarência e10 para pagamento. $O$ assunto obteve grandeespaço na mídia e indignação por parte de uma boa parcela da população, não só pelo valor do empréstimo, mastambém pelaforma esigilo com que as negociações foram conduzidas.

Assim como o condenado empréstimo, a questão ambiental também não foi questionada e debatida pela sociedade, porque quase não esteve presente na agenda da imprensa. Os jornais analisados somente aplaudiram ecomemoraram a vinda da nova empresa e todos os benefícios que por ela serão gerados. Conseqüentemente, a sociedade fez o mesmo.

Pelos princípios de interesse, exposição, percepção, recordação e ação seletiva, fica evidentequeo pensamento dagrandemaioria não teriasido al terado somentepela presença da questão ambiental na imprensa. Mas, essa presençadesencadeariacuriosidade, reflexão e provavelmente aquelas pessoas em cujo interior as informações encontrassem ressonânciaquestionariameexigiriamexplicações sobre as providências a serem tomadas e a participação do Estado nos seuscustos, assim como posteriormenteocorreu com relação ao empréstimo fornecido. O público aborda os assuntosquelhesão familiares, mas paraisso al guém precisa exigir queel es façam parteda pauta dos veículos.

A humanidade alcançará o almejado estágio deevolução e maturidade quando aprender a respeitar a natureza, quando existir uma consciência ambiental em todos os níveis da sociedade.

\section{Como isso se dará?}

Não será por meio de lutas e radicalismos de esquerda ou dedireita, maspelo diálogo entre os povos da Terra. Será através de uma permanentepresençadosassuntosambientais na agenda da imprensa. A naturezaéperfeita e não necessita do homem para se recuperar, mas precisaurgentementequeelearespeitee pare de destruí-la.

A GM está chegando com a previsão de se enquadrar nas normas ISO 14000? 
Algumas poucaseespaçadas vezeso impacto ambiental a ser gerado pelas suas futuras instalações foi abordado, sendo que nestas ocasiões as informações não receberam a devida importância.

Quanto aos efluenteslíquidos, real menteserá feito um sistema integrado semel hanteao do Pólo Petroquímico? Em caso positivo, que resultados estão sendo obtidos? Por qual tipo de tratamento passarão os efluentes cloacais que serão lançados no Rio Gravataí? E os industriais serão mesmo reutilizados na sua totalidade? No geral isso é muito difícil e parte deles são lançados no meio ambiente. É correto e moral que os custos do tratamento hídrico de uma empresa privada sejam arcados pelo contribuinte?

Onde ficam os terminais para resíduos sólidos? Que tipo de revestimento será utilizado no solo e qual é a sua segurança?

Quanto às emissões aéreas, as opções apresentadas são seguras?

Como cidadãos temos direito a todas estas respostas e principalmente no que se refere aos resíduos líquidos, já que serão custeados por nós.

Esses assuntos não obtiveram a merecida discussão junto à sociedade. A penas ocorreu uma verticalidade na comunicação e o tema, superficialmente tratado pela agenda da mídia, ficou em segundo plano para a população.

A conseqüência é o fato de a sociedade praticamente não haver refletido sobre a questão ambiental queenvolveráa instalação daGM no Rio Grandedo Sul. Por estemotivo arcarácomcustosfinanceiroseprovavelmente ambientais que ainda desconhece e sobre os quais não teve oportunidade de opinar.

Talvez, dentro de al gum tempo, mais algum deputado desperte para o assunto e então a questão ambiental obtenha o mesmo espaço destinado ao financiamento concedido à GM . Nessa ocasião todos sedarão conta dequeele foi muito maior do que RS $\$ 253$ milhões.

\section{Referências}

COHEN, B. The press and foreign policy. Princeton : Princeton University Press, 1963

DEFLEUR, Melvin L. et BALL- ROKEACH. Sandra. Teorias da comunicacăa de massa, 5. ed. Rio de Janeiro : Zahar, 1993.

FAUNDEZ, Antonio (org.). Educação, desenvolvimento e cultura. São Paulo : Cortez, 1994.

GUIMARÃES, Mauro. A dimensão ambiental na educação. Papirus Editora, 1992.

PETER Nelson. Dez dicas práticas para reportagens sobre 0 meio ambiente. The Center for Foreign Journalists, 1994.

REIGOTA, Marcos. 0 que é Educação Ambiental, São Paulo : Editora Brasiliense, 1994. v. 292 Coleção primeiros passos.

RODRIGUES, Aroldo. Psicologia Social. Vozes, 1988.

SHAW, E. "Agenda-Setting and Mass Communication Theory", Gazette, 1979, vol. XXV, ㄲo2.

WOLF, Mauro. Teorias da Comunicação. 4. ed. Lisboa : Editorial Presença, 1995. 